Short Communication

\title{
Seroprevalence and factors associated with Toxoplasma gondii-, Neospora caninum- and Coxiella burnetii-infections in dairy goat flocks from Costa Rica
}

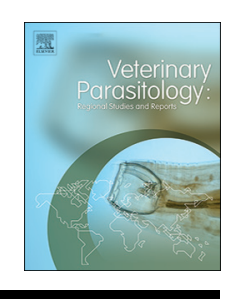

\author{
Rodolfo Villagra-Blanco ${ }^{\mathrm{a}, \mathrm{b}, \mathrm{c}, *}$, Andrea Esquivel-Suárez ${ }^{\mathrm{a}}$, Henrik Wagner ${ }^{\mathrm{b}}$, \\ Juan José Romero-Zúñiga ${ }^{\mathrm{a}}$, Anja Taubert ${ }^{\mathrm{c}}$, Axel Wehrend ${ }^{\mathrm{b}}$, Carlos Hermosilla ${ }^{\mathrm{c}}$, Gaby Dolz ${ }^{\mathrm{a}}$ \\ a Programa de Investigación en Medicina Poblacional, Escuela de Medicina Veterinaria, Universidad Nacional (UNA), P.O. Box 86-3000, Heredia, Costa Rica \\ ${ }^{\mathbf{b}}$ Clinic for Obstetrics, Gynecology and Andrology of Large and Small Animals with Veterinary Ambulance, Faculty of Veterinary Medicine, Justus Liebig University Giessen, \\ 35392 Giessen, Germany \\ ${ }^{\mathrm{c}}$ Institute of Parasitology, Faculty of Veterinary Medicine, Justus Liebig University Giessen, 35392 Giessen, Germany
}

\section{A R T I C L E I N F O}

\section{Keywords:}

Goats

ELISA

Zoonosis

Public-health

Costa Rica

\begin{abstract}
A B S T R A C T
A total of 391 goats from 13 dairy flocks from all Costa Rican regions were analyzed for Toxoplasma gondii-, Neospora caninum- and Coxiella burnetii-related seroprevalence by enzyme-linked immunosorbent assays (ELISA). Additionally, a risk factor analysis for these parasitic infections was performed based on a questionnaire considering several environmental and housing/management factors. A total of $62.1 \%(243 / 391)$ of individual serum samples revealed seropositive for T. gondii, 7.9\% (31/391) for $N$. caninum, and 1.8\% (7/391) for C. burnetii. At herd level, the overall seroprevalence for $T$. gondii was $100 \%$, for $N$. caninum $69.2 \%$ and for $C$. burnetii $7.7 \%$. However, no clinical signs related to toxoplasmosis, neosporosis or Q fever were apparent in these flocks. T. gondii-related risk factors were the contact with cats (OR = 3.44; CI 95\%; 2.0-5.91), dogs (OR = 5.75; CI 95\%; 2.84-11.66), and white-tailed deer (Odocoileus virginianus) (OR $=0.15$; CI 95\%; 0.08-0.26) within or around the farms. The presence of reproductive males in each flock (OR $=0.32$; CI 95\%; 0.14-0.74) and the coexistence of sheep (OR $=0.46$; CI 95\%; 0.2-1.08) and cattle (OR $=5.94$; CI 95\%; $1.70-20.78)$ revealed as protective and risk factors respectively for $N$. caninum infections. This study determined for the first time the seroprevalences of N. caninum, T. gondii and C. burnetii in Costa Rican goat flocks. Particularly, the high withinherd seroprevalences determined for $T$. gondii requires further surveillance to complement these findings.
\end{abstract}

\section{Introduction}

Toxoplasma gondii and Neospora caninum are two closely related apicomplexan parasites associated with reproductive disorders in ruminants, such as foetal reabsorption, mummification, abortion, stillbirth and neonatal losses, leading to substantial economic losses in livestock production (Reichel et al., 2013). Toxoplasma gondii also plays a considerable zoonotic role since the consumption of infected raw or undercooked meat or milk from ruminants has been demonstrated to cause human toxoplasmosis (Tenter et al., 2000). Coxiella burnetii is an intracellular gamma proteobacterium of the family Coxiellaceae, which causes reproductive disorders in small ruminants and $\mathrm{Q}$ fever in humans (Van den Brom et al., 2015). This pathogen can be transmitted by ticks and other arthropods, but the main source of infection for domestic animals and humans is exposure to parturient secretions by inhalation of contaminated aerosols (Woldehiwet, 2004).
In Costa Rica, seroprevalences of $T$. gondii were reported, so far, only in rodents (5\% in mice and $30.4 \%$ in rats; Chinchilla, 1978), cattle (34.4\%; Arias et al., 1994) and chicken (40.6\%; Abrahams-Sandi and Vargas-Brenes, 2005). The presence of Neospora-associated abortion was firstly described in Costa Rica in a dairy goat by Dubey et al. (1996). Further studies determined a dairy herd seroprevalence of 94.7\% (89/94), showing an overall individual seroprevalence of $43.3 \%$ (1185/2743) (Romero et al., 2005). Infections with $N$. caninum occur rather by vertical ( $64 \%$ of cases) than by horizontal transmission $(22 \%$ of cases) in Costa Rica, however the latter value is much higher than reported in other countries, probably due to the ecology and biodiversity of this country (Romero and Frankena, 2003). With respect to $C$. burnetii, respective DNA was not detected in milk powder samples from Costa Rica using real-time PCR analysis (Tilburg et al., 2012). So far and to the best of our knowledge, there are no data available on $T$. gondii and C. burnetii seroprevalences in small ruminants from Costa

\footnotetext{
* Corresponding author at: Institute of Parasitology, Justus Liebig University Giessen, Biomedical Research Center Seltersberg, Schubertstr. 81, 35392 Giessen, Germany.

E-mail address: Rodolfo.A.Villagra-Blanco@vetmed.uni-giessen.de (R. Villagra-Blanco).
} 
Rica. To fill this gap, the current study aimed to determine the seroprevalence of T. gondii, N. caninum and C. burnetii in goat flocks from Costa Rica, and to identify risk or protective factors being associated to seropositivity for these three pathogens.

\section{Materials and methods}

\subsection{Ethic statement}

The present study was conducted under the protocols established by the Animal Welfare Board (Comisión de Bienestar Animal) of the Universidad Nacional (Heredia, Costa Rica) and adhered to the legal requirements of the Animal Welfare Law (Ley 7451 de Bienestar Animal) of Costa Rica.

\subsection{Study population}

In the current study, exclusively flocks with dairy goat keeping of typical breeds, such as Saanen, Toggenburg, Anglo-Nubian and Alpine were included. The different flocks were registered in the database of the Small Ruminant Program of the National Animal Health Service (SENASA) of Costa Rica or affiliated to independent local caprine associations. The majority of analyzed flocks (69.2\%) kept a small number of animals ( $<100$ goats), mostly maintained under semi-intensive conditions $(61.5 \%)$. These animals were kept together with other domestic species, such as dogs (84.6\%), cattle (61.5\%), horses (53.8\%), pigs $(53.8 \%)$, poultry $(46.2 \%)$, cats $(46.2 \%)$, and sheep (38.5\%).

Required sample sizes were calculated according to data published by the National Institute of Statistics and Census (INEC) of Costa Rica in 2014, who reported a population of 12.852 goats, kept in 2.348 farms. The expected prevalence of anti-T. gondii (40\%), anti-N. caninum (7\%) and anti-C. burnetii antibodies (25\%) was estimated with $95.0 \%$ confidence level and using Win Episcope 2.0 (Thrusfield et al., 2001) to determine the representative number of animals to be tested. The serological survey was conducted in 391 goats for the three abortive agents using farms sampled nationwide as part of the surveillance program against brucellosis during 2013-2017 (Hernández-Mora et al., 2017). The Cannon and Roe's formula (1982) was used to determine the sample size to be analyzed in each flock ( $5 \%$ expected prevalence at $95.0 \%$ confidence level). The study was conducted in 13 Costa Rican goat flocks selected by their broodstock activities, where the abortions were more frequent to happen and with owners who were willing to participate (Hernández-Mora et al., 2017). For proportional allocation, the sample flocks were present along the six regions of Costa Rica: Central (five farms), North Huetar (three farms), Atlantic Huetar (two flocks), Central Pacific (one flock), Chorotega (one flock) and Brunca (one flock).

\subsection{Sample collection and survey}

The selection of the animals inside each flock was randomly performed. Blood sampling was performed by bleeding from the jugular vein using BD Vacutainer ${ }^{\circledR} 22 \mathrm{G} \times 1$ " needles with their respective plastic cap, adjusted to $6 \mathrm{ml}$ vacuum tubes for serum (without anticoagulant). Tubes were transported in coolers keeping a temperature between 5 and $10^{\circ} \mathrm{C}$. For serum isolation, blood samples were centrifuged for $8 \mathrm{~min}$ at $3500 \times \mathrm{g}$. Serum was frozen at $-20^{\circ} \mathrm{C}$ until further use. A questionnaire was applied to the farmers to assess possible risk factors being associated with $T$. gondii, $N$. caninum and C. burnetii serostatus. Therefore, information on housing conditions, management, animal feeding habits, goat kid husbandry, abortions and contact with other domestic/wild animals on the farm or/and the surroundings was prompted.

\subsection{Enzyme-linked immunosorbent assay (ELISA)}

The IDScreen ${ }^{\circledR}$ Toxoplasma gondii, Neospora caninum and Coxiella burnetii Indirect Multispecies ELISAs (IDVet ${ }^{\circledR}$, Montpellier, France) were used to detect parasite-specific antibodies in the caprine serum samples. These assays were reported to have a high sensitivity (T. gondii: $100 \%$; N. caninum: $99.6 \%$; C. burnetii: $100 \%$ ) and high specificity (T. gondii: 100\%; N. caninum: 98.9\%; C. burnetii: 100\%) (Proctor et al., 2008; Álvarez-García et al., 2013; Sidibe et al., 2013; IDVET, 2016). Serum samples were processed according to the manufacturer's protocol. The sera were diluted 1:10 for the analysis of each agent. For an adequate interpretation, the average of the optical densities (OD) of the positive controls, and the difference between averages of ODs of positive and negative control sera were calculated. Serum positive percentages (S/P) were calculated according to OD data from the different serum samples and the average of OD of the positive control sera, using the following formula: $S / P=(O D$ of sample $\times 100)$ : (average OD of positive control). As recommended by the manufacturer, the serum samples with $\mathrm{S} /$ $\mathrm{P}$ percentages $<40 \%$ were considered as negative; samples with $\mathrm{S} / P$ values between 40 and $50 \%$ were scored as inconclusive (considered negative in this study) and sera with $\mathrm{S} / \mathrm{P}$ values $>50 \%$ were determined as positive.

\subsection{Statistical analysis}

The overall and specific within-herd seroprevalences were assessed; besides, frequencies of the general characteristics and management conditions inside each goat flock were calculated. Factors associated with the agents were assessed by odds ratio (OR) estimation with the goat flock serving as the random variable. The causal variables with inferior and superior confidence intervals (CI 95\%) $\leq 1$ were considered as risk variable/factors, meanwhile protective variables/factors contained CI $95 \% \geq 1$. A non conditional logistic regression in two steps was used and first, an univariate analysis was performed for each independent variable and those ones with $\mathrm{p} \leq 0.25$ were retained and selected for the multivariate logistic regression model performed by a step-wise backward elimination (Hosmer and Lemeshow, 2005), which was evaluated by likelihood ratio tests. The data were analyzed using EGRET for Windows version 9.2 (Cytel Software Corporation).

\section{Results}

From a total of 391 caprine serum samples analyzed by ELISA, 243 reacted positive to $T$. gondii (62.14\%), 31 to $N$. caninum (7.92\%) and 7 to C. burnetii (1.79\%). Moreover, 20 animals were found positive for $N$. caninum and $T$. gondii $(5.12 \%)$ and just two goats $(0.5 \%)$ were positive for all three pathogens. $T$. gondii-specific antibodies were detected in all analyzed flocks (herd prevalence: 100\%), N. caninum-specific antibodies in nine flocks (69.2\%) from five regions, and C. burnetii-specific antibodies only in one flock $(7.7 \%)$ in the North Huetar Region. In general, the regional seropositivity varied considerably: $39.1 \%-88.3 \%$ for T. gondii, $0 \%-17.6 \%$ for N. caninum and $0 \%-5.5 \%$ for C. burnetii. Within each herd, the prevalences range from $13.3 \%$ to $95.3 \%$ for $T$. gondii and $0 \%$ to $23.5 \%$ for $N$. caninum. In the single seropositive flock, $15.2 \%$ of the goat samples contained C. burnetii-specific antibodies (Table 1). No clinical signs related to toxoplasmosis, neosporosis or $\mathrm{Q}$ fever were apparent in any flock under investigation.

The univariate analysis revealed the extensive farm management and the contact with domestic animals (pigs, sheep, dogs, cats) in the farm, as well as wild animals (coyotes, opossums, coatis, peccaries, raccoons, white-tailed deer) around the farms as risk factors for $T$. gondii seropositivity. Respective factors for $N$. caninum seropositivity were the presence of reproductive males (protective variable), a farm size with 10-50 goat kids (protective variable), adequate disposal of abortive materials (protective variable), and the co-existence of goats with bovines (risk factor) and sheep (protective variable) (Table 2). 
Table 1

Distribution of seronegative and seropositive sera to N. caninum, T. gondii and C. burnetii from goats of Costa Rica according to flock and region.

\begin{tabular}{|c|c|c|c|c|c|c|c|c|}
\hline \multirow[t]{2}{*}{ Flock } & \multirow[t]{2}{*}{ Region } & \multirow[t]{2}{*}{ Individuals tested/Animals in the flock (\%) } & \multicolumn{3}{|c|}{ Positive animals (\%) } & \multicolumn{3}{|c|}{ Regional seropositivity n (\%) } \\
\hline & & & N. caninum & T. gondii & C. burnetii & N. caninum & T. gondii & C. burnetii \\
\hline 1 & Central & $21 / 23(91.3)$ & $3(14.3)$ & $5(23.8)$ & $0(0.0)$ & 7.7 & 54.2 & 0.0 \\
\hline 2 & & $46 / 145(31.7)$ & $4(8.7)$ & $9(19.6)$ & $0(0.0)$ & & & \\
\hline 3 & & $17 / 18(94.4)$ & $4(23.5)$ & $4(23.5)$ & $0(0.0)$ & & & \\
\hline 4 & & $38 / 101(37.6)$ & $2(5.3)$ & $32(84.2)$ & $0(0.0)$ & & & \\
\hline 5 & & $46 / 64$ (71.9) & $0(0.0)$ & $41(89.1)$ & $0(0.0)$ & & & \\
\hline 6 & Brunca & $9 / 13(69.2)$ & $1(11.1)$ & $4(44.4)$ & $0(0.0)$ & 11.0 & 44.4 & 0.0 \\
\hline 7 & Atlantic Huetar & $15 / 15(100)$ & $2(13.3)$ & $2(13.3)$ & $0(0.0)$ & 8.7 & 39.1 & 0.0 \\
\hline 8 & & $8 / 9(88.9)$ & $0(0.0)$ & 7 (87.5) & $0(0.0)$ & & & \\
\hline 9 & Central Pacific & $17 / 18(94.4)$ & $3(17.6)$ & 9 (52.9) & $0(0.0)$ & 17.6 & 52.9 & 0.0 \\
\hline 10 & Chorotega & $46 / 66(69.7)$ & $0(0.0)$ & $17(37.0)$ & $0(0.0)$ & 0.0 & 37.0 & 0.0 \\
\hline 11 & North Huetar & $39 / 91$ (42.9) & $6(15.4)$ & 37 (94.8) & $0(0.0)$ & 9.4 & 88.3 & 5.47 \\
\hline 12 & & $46 / 213(21.6)$ & $6(13.0)$ & $35(76.1)$ & $7(15.2)$ & & & \\
\hline \multirow[t]{2}{*}{13} & & $43 / 102(42.2)$ & $0(0.0)$ & $41(95.3)$ & $0(0.0)$ & & & \\
\hline & TOTAL & 391 (44.7) & $31(7.92)$ & $243(62.14)$ & 7 (1.79) & & & \\
\hline
\end{tabular}

Since only seven goats from one single flock were positive for C. burnetii, no risk factor analysis could be performed.

Following the backward process, the final multivariate logistic regression model for $T$. gondii confirmed that contact with cats, dogs and white-tailed deer as risk factors to seropositivity. Meanwhile, three variables were confirmed for $N$. caninum seropositivity: the presence of more than two reproductive males (protective variable) and the coexistence with bovine (risk variable) and with sheep (protective factor) (Table 3).

\section{Discussion}

The current seroprevalence study provides data on T. gondii, $N$. caninum, and C. burnetii infections in domestic goats in Costa Rica. Thus, a high proportion of goats were detected seropositive for T. gondii $(62.14 \%)$. In line, similar $T$. gondii seroprevalences were recently reported in four Caribbean islands (58\% in Dominica, 57\% in Grenada,
$80 \%$ in Montserrat and $42 \%$ in Saint Kitts and Nevis) and Colombia (58\%) whilst in Mexico fewer animals revealed infected (31\%) (Alvarado-Esquivel et al., 2011; Cañón-Franco et al., 2014; Hamilton et al., 2014). All these authors agreed with a broad environmental contamination of $T$. gondii oocysts in soil, water, vegetables or fruits affecting small ruminant flocks.

In case of $T$. gondii infections, poor management practices (e. g. poor hygiene, lack of proper feeding, irregular vaccination, and deworming) and goat farming in close contact with other productive, companion or wild animals (univariate analysis), especially cats, dogs and whitetailed deer (multivariate analysis) were here identified as risk factors for T. gondii seropositivity, which is in agreement to other reports (Dubey et al., 1995; Liu et al., 2015; Bawm et al., 2016.). The most obvious risk factor is related to the co-existence of goats with cats since these may shed high numbers of oocysts which contaminate the environment. In agreement, Frenkel and Ruiz (1981) assumed that the endemicity of $T$. gondii in Costa Rica is due to the high cat population.

Table 2

Univariate analyses of risk factors associated with $N$. caninum and T. gondii seropositivity in 13 goat flocks from Costa Rica.

\begin{tabular}{|c|c|c|c|c|c|}
\hline \multirow[t]{3}{*}{ Variable } & \multirow[t]{3}{*}{ Category } & \multicolumn{4}{|c|}{ Neospora caninum } \\
\hline & & \multicolumn{4}{|l|}{ CI 95\% } \\
\hline & & p-Value & OR & IL & UL \\
\hline Number of goat kids & $11-50$ & 0.031 & 0.23 & 0.05 & 1.23 \\
\hline Number of males & $>2$ & 0.038 & 0.44 & 0.18 & 1.01 \\
\hline Disposal of abortive materials & Burial & 0.019 & 0.37 & 0.15 & 0.95 \\
\hline Co-existence with bovines & Yes & 0.007 & 4.55 & 1.28 & 19.19 \\
\hline Co-existence with sheep & Yes & 0.062 & 0.46 & 0.18 & 1.11 \\
\hline \multirow[t]{3}{*}{ Variable code } & Category & \multicolumn{4}{|c|}{ Toxoplasma gondii } \\
\hline & & \multicolumn{4}{|l|}{ CI 95\% } \\
\hline & & p-Value & OR & $\mathrm{IL}$ & UL \\
\hline Husbandry system & Extensive & $<0.001$ & 0.09 & 0.01 & 0.44 \\
\hline Contact with swine & Yes & $<0.001$ & 2.05 & 1.32 & 3.20 \\
\hline Co-existence of sheep & Yes & $<0.001$ & 0.35 & 0.22 & 0.55 \\
\hline Contact with cats & Yes & $<0.001$ & 5.19 & 3.22 & 8.38 \\
\hline Contact with dogs & Yes & $<0.001$ & 4.39 & 2.42 & 8 \\
\hline Contact with coyotes & Yes & $<0.001$ & 0.24 & 0.14 & 0.39 \\
\hline Contact with opossums & Yes & $<0.001$ & 0.17 & 0.10 & 0.27 \\
\hline Contact with coatis & Yes & $<0.001$ & 0.15 & 0.09 & 0.25 \\
\hline Contact with peccaries & Yes & $<0.001$ & 0.15 & 0.09 & 0.24 \\
\hline Contact with raccoons & Yes & $<0.001$ & 0.09 & 0.05 & 0.16 \\
\hline Contact with white-tailed deer & Yes & $<0.001$ & 0.30 & 0.19 & 0.48 \\
\hline
\end{tabular}

Codes: OR = Odds ratio; IL = Inferior limit; UL = Upper limit; CI = Confidential interval. 
Table 3

Risk factors associated with $N$. caninum and T. gondii seropositivity in 13 goat flocks from Costa Rica according to the multivariate logistic regression model.

\begin{tabular}{|c|c|c|c|c|c|c|c|c|}
\hline \multirow[t]{3}{*}{ Variable } & \multicolumn{4}{|c|}{ N. caninum } & \multicolumn{4}{|l|}{ T. gondii } \\
\hline & \multicolumn{4}{|l|}{ CI 95\% } & \multicolumn{4}{|l|}{ CI 95\% } \\
\hline & p-Value & OR & IL & UL & p-Value & OR & IL & UL \\
\hline $\begin{array}{l}\text { More than two } \\
\text { reproductive } \\
\text { bucks }\end{array}$ & 0.008 & 0.32 & 0.14 & 0.74 & - & - & - & - \\
\hline $\begin{array}{l}\text { Co-existence of } \\
\text { bovine }\end{array}$ & 0.005 & 5.94 & 1.70 & 20.78 & - & - & - & - \\
\hline $\begin{array}{l}\text { Co-existence of } \\
\text { sheep }\end{array}$ & 0.076 & 0.46 & 0.20 & 1.08 & - & - & - & - \\
\hline Contact with cats & - & - & - & - & $<0.001$ & 3.44 & 2.00 & 5.91 \\
\hline $\begin{array}{c}\text { Contact with } \\
\text { dogs }\end{array}$ & - & - & - & - & $<0.001$ & 5.75 & 2.84 & 11.66 \\
\hline $\begin{array}{l}\text { Contact with } \\
\text { white-tailed } \\
\text { deer }\end{array}$ & - & - & - & - & $<0.001$ & 0.15 & 0.08 & 0.26 \\
\hline
\end{tabular}

Codes: $\quad$ OR = Odds $\quad$ ratio; $\quad \mathrm{IL}=$ Inferior $\quad$ limit; $\quad \mathrm{UL}=$ Upper $\quad$ limit; $\mathrm{CI}=$ Confidential interval.

The unlimited contact between goats and free-roaming cats has been described as important risk factor in extensive management systems related to high herd-level seroprevalences (Czopowicz et al., 2011). In the other hand, dogs may also play an important role on the transmission of $T$. gondii since they could be affected by coprophagia when they have ingested feces of infected cats (Schares et al., 2005). Here is important to clarify, despite dogs themselves do not produce oocysts, high contaminated environments with $T$. gondii and $H$. hammondi oocysts represent a source for other animals, particularly in areas with dense populations of stray and guard dogs, who shed coprophaged/ excreted oocysts after intestinal passage, which possibly explains the roll of dogs as a risk factor of $T$. gondii in the surrounding goat populations (Schares et al., 2005; Hosseininejad et al., 2011). However, further deep analysis on the mechanisms involving coprophaged/excreted oocysts by dogs and their posterior infection in small ruminants should be performed. Additionally, wildlife mammals were also identified as risk factor of toxoplasmosis, since these animals are also susceptible wild intermediate hosts of this polyxenous apicomplexan parasite, which prolong the parasite's life cycle when wild felines feed on their infected carcases, as documented by several studies (Solorio et al., 2010; Dubey et al., 2014).

In case of $N$. caninum, the lower overall seroprevalence observed in the present study $(7.92 \%)$ agreed with data published in other Latin American reports, such as Moore et al., 2007 in Argentina (6.6\%), Topazio et al. (2014) in Brazil (4.58\%) and Sharma et al. (2015) in Grenada (5.8\%). Moreover, Dubey et al. (2017) reported that worldwide caprine $N$. caninum seroprevalences range between 0 and $26 \%$, which agree with our results. In contrast to goats, $N$. caninum infections are well established in cattle, thus a considerably higher overall $N$. caninum seroprevalence of $39.7 \%$ was found in Costa Rican dairy cattle (Romero and Frankena, 2003). The lower caprine $N$. caninum seroprevalence might be influence by the duration of the infection, the seroconversion and the applied serological tests, modifying the dynamics of the antibodies (Dubey et al., 2017). As expected, instant removal of placentas and fetuses performed by most Costa Rican goat farmers $(\mathrm{OR}=0.37$; CI 95\%; 0.15-0.95) revealed as an important protective factor for caprine neosporosis, as already described by Dubey et al. (2007). However, N. caninum infections in Costa Rica seemed mainly to be influenced by ruminant sharing grazing (Liu et al., 2015), either through the permanence of caprine with bovine (risk variable) or/and ovine (protective variable) species. Recent literature associated pastures highly contaminated with $N$. caninum oocysts with flocks where the animal density was extremely elevated and ruminant sharing grazing practices were common, thus promoting horizontal transmission of this parasite (Haddad et al., 2005; Armengol et al., 2007).

The presence of reproductive males was found as a protective factor against caprine neosporosis; which may be based on the assumption that bucks may be less susceptible to this infection than females, due to the absence of immunosuppression periods during pregnancy (HuertaPeña et al., 2011). Enhanced innate immune responses against $T$. gondii and $N$. caninum infections have been mentioned in caprine males than in females in numerous studies, therefore female goats demonstrated higher seropositivity (van der Puije et al., 2000; Uzêda et al., 2004; Sharma et al., 2015). Moreover, as the risk of sexual transmission of $N$. caninum is relative low (Ortega-Mora et al., 2003), we suggest that transportation of goats for mating would break the biosecurity cycle of $N$. caninum-free farms, particularly when goats are brought into flocks with reproductive bucks under different management conditions. This situation might justify the presence of males as a protective variable in the present study. However, the biological role of sex in apicomplexan infection and transmission in the caprine systems must be investigated further.

In eight flocks, $N$. caninum seropositive goats $(20 / 31 ; 64.5 \%)$ were also $T$. gondii positive. These mixed infections were most probably due to management practices, abortions and significant contact with cats ( $T$. gondii, $\mathrm{OR}=3.44$; CI 95\%; 2.0-5.91) and dogs ( $N$. caninum, $\mathrm{OR}=5.75$; CI 95\%; 2.84-11.66) (Topazio et al., 2014; Gos et al., 2017).

The low seroprevalence of $C$. burnetii was similar to that determined by Gardon et al. (2001) in livestock from French Guiana (1.7\%). Interestingly, the only flock with positive animals was located near to the border with Nicaragua. In this country, $C$. burnetii was recently reported to cause acute febrile illness in humans (Reller et al., 2016). In future work, $C$. burnetii-related data should be verified additionally via molecular techniques.

Finally, no clinical signs related to toxoplasmosis, neosporosis or $\mathrm{Q}$ fever were detected in any analyzed flocks, which can be related to several variables, such as stage of infection, pathogen strains, seroconversion and the animal immunity, as previously reported in the literature (Bezerra et al., 2013; Porto et al., 2016; Muleme et al., 2017). The absence of clinical reproductive signs (e. g. abortions and infertility) and their relationship with these mentioned variables (particularly with seroconversion) suggests also the presence of persistent or latent infected goats in these flocks, but their confirmation using immunoblot techniques are necessary to assess this hypothesis. Furthermore, the elevated cost in the importation of further diagnostic tools in Costa Rica was the principal limitation of our study that impeded the use of other detection methods as confirmation of our results. Therefore, we highly recommend the use of alternative diagnostic tools, such as PCR or immunoblot in further studies to confirm and complement the obtained data through the identification of particular pathogenantigens.

\section{Conclusions}

This study determined for the first time seroprevalences of $N$. $c a$ ninum, $T$. gondii and $C$. burnetii in goat flocks from all Costa Rican regions: all flocks were infected with $T$. gondii; $N$. caninum was found in nine flocks (69.2\%), and C. burnetii only in one flock. Furthermore, risk and protective factors associated to seropositivity were identified: $T$. gondii infection was related with the contact of goats with cats, dogs and white-tailed deer in the farms, whereas $N$. caninum was linked to joint grazing of goats with cattle and sheep. It is important to inform the caprine producers on these results; to keep definitive hosts (dogs and cats) separated from the grazing fields, prevent them (and wild animals) to wander in pastures and feed on abortive material. It is also recommended to avoid the sharing of paddocks between cows, goats and wild ruminants, especially the maternity paddocks, and adequate management practices inside the flock to prevent transmission of apicomplexan parasites. Complementary molecular detection is necessary 
to confirm the presence of $C$. burnetii in Costa Rica. Finally, further epidemiological surveillance for caprine toxoplasmosis and coxiellosis is recommended.

\section{Ethics approval and consent to participate}

Not applicable.

\section{Consent for publication}

Not applicable.

\section{Availability of data and material}

All data generated or analyzed during this study were included in this published article.

\section{Funding}

This work was funded by Fundación Universidad Nacional (FUNDAUNA) under the project "Presencia, prevalencia y epidemiología de agentes infecciosos en pequeños rumiantes de Costa Rica" and the Ministerio de Ciencia, Tecnología y Telecomunicaciones (MICITT-Costa Rica) through the PINN program (PND-026-15-2) designated for the $\mathrm{PhD}$ candidate RVB at the Justus Liebig University (JLU) Giessen, Germany.

\section{Author's contributions}

RVB, GD and AES collaborated with the sample collection and survey. RVB and GD performed the ELISA analysis. RVB, HW, JJR, AW, AT, CH and GD cooperated in research design, data analysis and manuscript's review. All the authors corrected and accepted the final manuscript.

\section{Conflict of interest statement}

The authors ratified that they have no competing interests in the present study.

\section{Acknowledgements}

We acknowledge and thank all goat farmers who agreed to participate in this study. We also wish to thank Gabriela Hernández-Mora (DVM), Anthony Solórzano (M.Sc.), Danilo Montero-Caballero (DVM, M.Sc.) and Marta Bonilla (DVM, M.Sc.) for their technical and professional assistance.

\section{References}

Abrahams-Sandi, E., Vargas-Brenes, O., 2005. Serological prevalence of Toxoplasma gondii in free-range chickens from Costa Rica. Trop. Anim. Health Prod. 37 (5), 369-372. Alvarado-Esquivel, C., García-Machado, C., Vitela-Corrales, J., Villena, I., Dubey, J.P., 2011. Seroprevalence of Toxoplasma gondii infection in domestic goats in Durango State, Mexico. Vet. Parasitol. 183, 43-46.

Álvarez-García, G., García-Culebras, A., Gutiérrez-Exposito, D., Navarro-Lozano, V., Pastor-Fernández, I., Ortega-Mora, L.M., 2013. Serological diagnosis of bovine neosporosis: a comparative study of commercially available ELISA tests. Vet. Parasitol. 198, 85-95.

Arias, M.L., Chinchilla, M., Reyes, L., Sabah, J., Guerrero, O.M., 1994. Determination of Toxoplasma gondii in several organs of cattle by carbon immunoassay (CIA) testing. Vet. Parasitol. 55, 133-136.

Armengol, R., Pabon, M., Santolaria, P., Cabezon, O., Adelantado, C., Yaniz, J., LopezGatius, F., Almeria, S., 2007. Low seroprevalence of Neospora caninum infection associated with the Limousin breed in cow-calf herds in Andorra, Europe. J. Parasitol. 93, 1029-1032.

Bawm, S., Maung, W.Y., Win, M.Y., Thu, M.J., Chel, H.M., Khaing, T.A., Wai, S.S., Htun, L.L., Myaing, T.T., Tiwananthagorn, S., Igarashi, M., Katakura, K., 2016. Serological survey and factors associated with Toxoplasma gondii infection in domestic goats in Myanmar. Scientifica (Cairo) 4794318.
Bezerra, M.J.G., Kim, P.C.P., Moraes, E.P.B.X., Sa, S.G., Albuquerque, P.P.F., Silva, J.G., Alves, B.H.L.S., Mota, R.A., 2013. Detection of Toxoplasma gondii in the milk of naturally infected goats in the Northeast of Brazil. Transbound. Emerg. Dis. 62 (4). https://doi.org/10.111/tbed.12160. 421-4.

Cannon, R.M., Roe, R.T., 1982. Livestock Disease Survey: A Field Manual for Veterinarians. Australian Government Publishing Service, Canberra, Australia.

Cañón-Franco, W.A., López-Orozco, N., Gómez-Marín, J.E., Dubey, J.P., 2014. An overview of seventy years of research $(1944-2014)$ on toxoplasmosis in Colombia, South America. Parasit. Vectors 7, 427.

Chinchilla, M., 1978. Epidemiología de la toxoplasmosis en Costa Rica y la importancia de los roedores domésticos. Rev. Biol. Trop. 26, 113-124.

Czopowicz, M., Kaba, J., Szalus-Jordanow, O., Nowicki, M., Witkowski, L., Frymus, T., 2011. Seroprevalence of Toxoplasma gondii and Neospora caninum infections in goats in Poland. Vet. Parasitol. 178, 339-341.

Dubey, J.P., Weigel, R.M., Siegel, A.M., Thulliez, P., Kitron, U.D., Mitchell, M.A., Mannelli, A., Mateus-Pinilla, N.E., Shen, S.K., Kwok, O.C., Todd, K.S., 1995. Sources of reservoirs of Toxoplasma gondii infection on 47 swine farms in Illinois. J. Parasitol. $81,723-729$.

Dubey, J.P., Morales, J.A., Villalobos, P., Lindsay, D.S., Blagburn, B.L., Topper, M.J., 1996. Neosporosis-associated abortion in a dairy goat. J. Am. Vet. Med. Assoc. 208, 263-265.

Dubey, J.P., Schares, G., Ortega-Mora, L.M., 2007. Epidemiology and control of neosporosis and Neospora caninum. Clin. Microbiol. Rev. 20, 323-367.

Dubey, J.P., Dennis, P.M., Verma, S.K., Choudhary, S., Ferreira, L.R., Oliveira, S., Kwok, O.C., Butler, E., Carstensen, M., Su, C., 2014. Epidemiology of toxoplasmosis in white tailed deer (Odocoileus virginianus): occurrence, congenital transmission, correlates of infection, isolation, and genetic characterization of Toxoplasma gondii. Vet. Parasitol. 202 (3-4), 270-275.

Dubey, J.P., Hemphill, A., Calero-Bernal, R., Schares, G., 2017. Neosporosis in Animals. Boca Raton Florida. CRC Press, USA.

Frenkel, J.K., Ruiz, A., 1981. Endemicity of toxoplasmosis in Costa Rica. Transmission between cats, soil, intermediate hosts and humans. Am. J. Epidemiol. 113, 254-269.

Gardon, J., Héraud, J.M., Laventure, S., Ladam, A., Capot, P., Fouquet, E., Favre, J., Weber, S., Hommel, D., Hulin, A., Couratte, Y., Talarmin, A., 2001. Suburban transmission of Q fever in French Guiana: evidence of a wild reservoir. J. Infect. Dis. $184,278-284$.

Gos, M.L., Manazza, J.A., Späth, E.J.A., Pardini, L., Fiorentino, M.A., Unzaga, J.M., More, G., Venturini, M.C., 2017. Seroprevalence of Toxoplasma gondii and Neospora caninum infections in goats from two Argentinean provinces. Open Vet. J. 7 (4), 319-322.

Haddad, J.P.A., Dohoo, I.R., Vanleewen, J.A., 2005. A review of Neospora caninum in dairy and beef cattle - a Canadian perspective. Can. Vet. J. 46 (3), 230-243.

Hamilton, C.M., Katzer, F., Innes, E.A., Kelly, P.J., 2014. Seroprevalence of Toxoplasma gondii in small ruminants from four Caribbean islands. Parasit. Vectors 7, 449.

Hernández-Mora, G., Bonilla-Montoya, R., Barrantes-Granados, O., Esquivel-Suárez, A. Montero-Caballero, D., González-Barrientos, R., Fallas-Monge, Z., Palacios-Alfaro, J.D., Baldi, M., Campos, E., Chanto, G., Barquero-Calvo, E., Chacón-Díaz, C., ChavesOlarte, E., Guzmán-Verri, C., Romero-Zúñiga, J.J., Moreno, E., 2017. Brucellosis in mammals of costa rica: an epidemiological survey. PLoS ONE 12 (8), e0182644.

Hosmer, D.W., Lemeshow, S., 2005. Wiley Series in Probability and Statistics, in Applied Logistic Regression, Second Edition. John Wiley \& Sons, Inc, Hoboken, NJ, USA. https://doi.org/10.1002/0471722146.scard.

Hosseininejad, M., Malmasi, A., Hosseini, F., Selk-Ghaffari, M., Khorrami, N., Mohebali, M., Shojaee, S., Mirani, A., Azizzadeh, M., Mirshokraei, P., Aliari, A., 2011. Seroprevalence of Toxoplasma gondii infection in dogs in Tehran, Iran. Iran. J. Parasitol. 6, 81-85.

Huerta-Peña, J.C., Martínez-Herrera, D.I., Peniche-Cardeña, A.E.J., Villanueva-Valencia, M., Hernández-Ruiz, S.G., Villagómez-Cortes, J.A., Barradas-Piña, F.T., MoralesÁlvarez, J.F., Flores-Castro, R., 2011. Seroprevalence and risk factors associated with Neospora caninum in goats from municipalities of central region of Veracruz. Trop. Subtrop. Agroecosys. 13, 445-454.

IDVET, 2016. ID Screen ${ }^{\circledR}$ Q Fever Indirect Multi-Species Sensitivity Quality Control Data Sheet [Pamphlet]. Montpellier, France. https://www.id-vet.com/produit/id-screenq-fever-indirect-multi-species/.

Liu, Z.K., Li, J.Y., Pan, H., 2015. Seroprevalence and risk factors of Toxoplasma gondii and Neospora caninum infections in small ruminants in China. Prev. Vet. Med. 118, 488-492.

Moore, D.P., de Yañiz, M.G., Odeón, A.C., Cano, D., Leunda, M.R., Späth, E.A.J., Campero, C.M., 2007. Serological evidence of Neospora caninum infections in goats from La Rioja Province. Argentina. Small Rumin Res. 73, 256-258.

Muleme, M., Campbell, A., Stenos, J., Devlin, J.M., Vincent, G., Cameron, A., Graves, S., Wilks, C.R., Firestone, S., 2017. A longitudinal study of serological responses to Coxiella burnetii and shedding at kidding among intensively-managed goats supports early use of vaccines. Vet. Res. 48, 50 .

Ortega-Mora, L.M., Ferre, I., del Pozo, I., Caetano Da Silva, A., Collantes-Fernández, E., Regidor-Cerrillo, J., Ugarte-Garagalza, C., Aduriz, G., 2003. Detection of Neospora caninum in semen of bulls. Vet. Parasitol. 117, 301-308.

Porto, W.J., Regidor-Cerrillo, J., de Cassia Peixoto Kim, P., Benavides, J., Dos Santos Silva, A.C., Horcajo, P., da Fonseca-Oliveira, A.A., Ferre, I., Mota, R.A., Ortega- Mora, L.M., 2016. Experimental caprine neosporosis: the influence of gestational stage on the outcome of infection. Vet. Res. 47, 29.

Proctor, A.F., O'Donovan, J., Marques, P.X., Gutierrez, J., Sammin, D., Brady, C., Worrall, S., Nally, J.E., Bassett, H., Markey, B.K., 2008. Detection of antibodies to Toxoplasma gondii in serum from experimentally infected pregnant ewes. In: University College Dublin, UCD, School of Agriculture, Food Science and Veterinary Medicine Research Day, 4th December.

Reichel, M.P., Alejandra Ayanegui-Alcerreca, M., Gondim, L.F., Ellis, J.T., 2013. What is 
the global economic impact of Neospora caninum in cattle - the billion dollar question. Int. J. Parasitol. 43, 133-142.

Reller, M.E., Chikeka, I., Miles, J.J., Dumler, J.S., Woods, C.W., Mayorga, O., Matute, A.J., 2016. First identification and description of Rickettsioses and Q fever as causes of acute febrile illness in Nicaragua. PLoS Negl. Trop. Dis. 10 (12), e0005185.

Romero, J.J., Frankena, K., 2003. The effect of the dam-calf relationship on serostatus to Neospora caninum on 20 Costa Rican dairy farms. Vet. Parasitol. 114, 159-171.

Romero, J.J., van Breda, S., Vargas, B., Dolz, G., Frankena, K., 2005. Effect of neosporosis on productive and reproductive performance of dairy cattle in Costa Rica. Theriogenol 64 (9), 1928-1939.

Schares, G., Pantchev, N., Barutzki, D., Heydorn, A.O., Bauer, C., Conraths, F.J., 2005. Oocysts of Neospora caninum, Hammondia heydorni, Toxoplasma gondii and

Hammondia hammondi in faeces collected from dogs in Germany. Int. J. Parasitol. 35 (14), 1525-1537.

Sharma, R.N., Bush, J., Tiwari, K., Chikweto, A., Bhaiyat, M.I., 2015. Seroprevalence of Neospora caninum in sheep and goats from Grenada, West Indies. Open J. Vet. Med. 5, 219-223.

Sidibe, S.S., Coulibaly, K.W., Dakouo, M., Tarnagda, Z., Sery, A., Niang, M., Traore, K., Nantoume, H., Diarra, S., Seyni, H., 2013. Q fever in small ruminants in Mali. Results of a serological survey. Revue d'élevage et de médicine vétérinaire des pays tropicaux 66 (1), 11-18.

Solorio, M.R., Gennari, S.M., Soares, H.S., Dubey, J.P., Hartley, A.C.Z., Ferreira, F., 2010. Toxoplasma gondii antibodies in wild white-lipped peccary (Tayassu pecari) from Peru. J. Parasitol. 96 (6), 1232.
Tenter, A.M., Heckeroth, A.R., Weiss, L.M., 2000. Toxoplasma gondii: from animals to humans. Int. J. Parasitol. 30 (12-13), 1217-1258.

Thrusfield, M., Ortega, C., de Blas, I., Noordhuizen, J.P., Frankena, K., 2001. WIN EPISCOPE 2.0: improved epidemiological software for veterinary medicine. Vet. Rec. $148,567-572$.

Tilburg, J.J., Roest, H.J., Nabuurs-Franssen, M.H., Horrevorts, A.M., Klaassen, C.H., 2012 Genotyping reveals the presence of a predominant genotype of Coxiella burnetii in consumer milk products. J. Clin. Microbiol. 50, 2156-2158.

Topazio, J.P., Weber, A., Camillo, G., Vogel, F.F., Machado, G., Ribeiro, A., Moura, A.B., Lopes, L.S., Tonin, A.A., Soldá, N.M., Bräunig, P., Silva, A.S., 2014. Seroprevalence and risk factors for Neospora caninum in goats in Santa Catarina state, Brazil. Rev. Bras. Parasitol. Vet. 23, 360-366. https://doi.org/10.1590/S1984-29612014062.

Uzêda, R.S., Fernández, S.Y., Jesus, E.E.V., Pinheiro, A.M., Ayres, M.C.C., Spinola, S., Barbosa Junior, H.V., Almeida, M.A.O., 2004. Fatores relacionados á presença de anticorpos IgG anti- Toxoplasma gondii em caprinos leiteiros do Estado da Bahia. Rev. Bras. Saúde Prod. Anim. 5, 1-8.

Van den Brom, R., van Engelen, E., Roest, H.I.J., van der Hoek, W., Vellema, P., 2015 Coxiella burnetii infections in sheep or goats: an opinionated review. Vet. Microbiol. 181 (1-2), 119-129.

van der Puije, W.N.A., Bosompem, K.M., Canacoo, E.A., Wastling, J.M., Akanmori, B.D., 2000. The prevalence of anti-Toxoplasma gondii antibodies in Ghanaian sheep and goats. Acta Trop. 76, 21-26.

Woldehiwet, Z., 2004. Q fever (coxiellosis): epidemiology and pathogenesis. Res. Vet. Sci. 77, 93-100. 